\title{
Entre o WhatsApp e a praça da "família": relato de uma experiência teórico-metodológica
}

Amanda Nogueira de Oliveira

Mestra em Comunicação pela Universidade Federal do Ceará e especialista em Teorias da Comunicação e da Imagem pela mesma universidade.

E-mail: amandanogueira.jor@gmail.com

Alexandre Barbalho

Professor dos Programas de Pós-Graduação em Sociologia e em Políticas Públicas da Universidade Estadual do Ceará e em Comunicação da Universidade Federal do Ceará.

Doutor em Comunicacão e Cultura Contemporâneas pela Universidade Federal da Bahia e estágio pós-doutoral na Universidade Nova de Lisboa.

E-mail: alexandrealmeidabarbalho@gmail.com

Resumo: Este artigo reflete a experiência teórico-metodológica possibilitada pela pesquisa que teve como objetivo compreender os processos de sociabilidade entre jovens reunidos em torno do grupamento autodenominado "família Os poderosos e as poderosas" e que se conectavam por meio de redes sociais e nas praças da cidade de Fortaleza, Ceará, entre março e novembro de 2015. A questão geradora era: como se constituíam essas relações, seus deslocamentos e rupturas, a partir da convergência entre os usos de tecnologias de comunicação e informação e das praças? Para os fins da pesquisa, utilizou-se como procedimentos metodológicos principais a etnografia e a netnografia.

Palavras-chave: juventude; redes sociais; etnografia; netnografia.
Abstract: This article reports the theoretical and methodological experience allowed by a research with the objective of understanding the processes of sociability among young people who formed a group named "família Os poderosos e as poderosas" (family The powerful men and women), who connected themselves through social networks and in the city squares of Fortaleza, Ceará, Brazil. The generating question was: how these relations occur, their dislocations and ruptures from the convergence between the use of communication and information technologies and at the squares? The main methodological procedures used on this research were ethnography and netnography.

Keywords: youth; theory; methodology; ethnography; netnography. 


\section{INTRODUÇÃO}

O objetivo deste artigo é relatar a experiência teórico-metodológica possibilitada pela pesquisa intitulada "A família 'Os poderosos e as poderosas': percursos juvenis entre o WhatsApp e a praça".

Wright Mills defende que "somente pela conversação na qual os pensadores experimentados trocam informações sobre suas formas práticas de trabalho será possível transmitir ao estudante iniciante um senso útil de método e teoria" 2 . Assim, acreditamos que a troca é sempre bem-vinda quando se trata de pesquisar o social, em especial se o "objeto" é essa parcela da população, a juventude, que como constructo se caracteriza por sua pluralidade e mutabilidade.

Já na década de 1960, Walter Jaide constatou a "multiplicidade de atitudes" entre jovens da mesma geração, o que o levou a duvidar da possibilidade de uma "característica universal de uma geração" que nivelaria as diferenças constatadas empiricamente ${ }^{3}$. Foi para acessar essas multiplicidades que entramos em campo. Nosso objetivo era compreender como se davam os processos de sociabilidade entre jovens reunidos em torno de um grupamento autodenominado "família", que se conectavam por meio de redes sociais e nas praças de bairros populares de Fortaleza, Ceará.

Nosso pressuposto era o de que os espaços de sociabilidade gerados tanto pela cidade como pelas tecnologias se constituíam de fluxos que resultavam não em justaposição, mas em híbridos, espécies de "redes dobradas" - ambientes multiplicados, paralelos e porosos, entre os quais há intensa troca ${ }^{4}$.

Para dar conta desses espaços, utilizamos como procedimento metodológico a etnografia, que não se esgotou na ida às praças, pois foi utilizada para acompanhar os diálogos no ambiente do WhatsApp, usado sistematicamente pelos membros da "família Os poderosos e as poderosas". A pesquisadora foi inserida nos grupos de WhatsApp ainda no começo de 2015 e realizou uma série de prints das conversas que os jovens estabeleciam nesses espaços agregativos.

É essa aventura metologógica que relatamos nas partes que seguem,

1. A pesquisa foi desenvolvida por Amanda Nogueira, sob orientação do professor Alexandre Barbalho, no mestrado em Comunicacão da Universidade Federal do Ceará.

2. MILLS, Wright. A imaginação sociológica. Rio de Janeiro: Zahar, 1969, p. 211.

3. JAIDE, Walter. As ambiguidades do conceito de "geração". In: BRITTO, Sulamita de (Org.). Sociologia da juventude II: para uma sociologia diferencial. Rio de Janeiro: Zahar, 1968. p. 15-28. tendo em mente o caráter experimental dos textos etnográficos e que a experiência da etnografia é sempre única e, portanto, difícil de se estabeler em um padrão.

\section{DECIDINDO O CAMPO EM MEIO À CIDADE}

A cidade possibilita experiências que acontecem de forma única e diferenciada para cada um de seus habitantes e visitantes. Essa experiência é resultado de escolhas individuais, mas nem por isso aleatórias. Como observa Magnani, a relação com a cidade resulta "de rotinas cotidianas, ditadas por injunções coletivas que regulam o trabalho, a devoção, a diversão, a convivência" ${ }^{5}$.

No que diz respeito à juventude, várias pesquisas foram desenvolvidas na perspectiva de compreender sua inserção no meio urbano e, particularmente, 
a importância dos meios de comunicação de massa nessa relação. Assim, foram criadas nomenclaturas para dar conta desse fenômeno, tais como geração X e Y, culminando no que seria o surgimento de uma "geração digital" (geração Z). Para Campos, esta é composta por indivíduos "perfeitamente familiarizados com os códigos e com os processos de gestão da informação audiovisual em circulação por múltiplas redes" ${ }^{6}$.

É o caso, por exemplo, da relação dos jovens com seus aparelhos celulares. Tais dispositivos, que oferecem uma série de funções, transformam o trajeto da juventude na cidade por meio de formas de consumo bastante diferenciadas em sua cotidianidade. André Lemos aponta como dispositivos desse tipo, que denomina "híbrido móvel de conexão multirrede", reconfiguram "as práticas sociais de mobilidade informacional pelos espaços físicos das cidades" enorme variedade de formatos e cores, o aparelho se transforma em uma forma de comunicação das atitudes dos jovens.

É essencial entender, ainda, que, em tempos de compartilhamento de informações e oportunidade de conectividade prolongada, acumular "capital tecnológico" é uma forma de os indivíduos se distinguirem nos mais variados campos, inclusive no social ${ }^{8}$. No caso dos jovens, na construção de uma relação frenética com o urbano, este acaba se firmando, simultaneamente, como palco e como tela.

Nesse ambiente citadino foi que se deu o primeiro contato com a família, logo no começo de 2015, durante o exercício de andar pela cidade, principalmente pelas ruas da Regional $\mathrm{VI}^{9}$. Na realidade, o olhar do pesquisador já estava acionado desde antes, em busca de um "objeto" de pesquisa. Assim, entre junho e agosto de 2014, visitamos o bairro Boa Vista, acompanhando skatistas em seu cotidiano, por conta da relação constante entre eles e a rua na utilização do espaço público como ambiente de encontro (percepção apoiada em pesquisas de campo prévias). Nesse trajeto constatamos que os jovens, ainda que mantivessem costumes tradicionais, como o de sentar nas calçadas para conversar com vizinhos e familiares, eram transformados pelo uso do celular - mesmo no espaço público, mantinham sua atenção voltada para o dispositivo, por meio do qual permaneciam trocando informações ${ }^{10}$. Compreendemos naquele momento o quanto as sociabilidades estavam diluídas entre o físico e o não presencial ${ }^{11}$.

Mas quando, em uma sexta-feira à noite, em fevereiro de 2015, observamos na praça do Lago Jacarey, situada em outro bairro da mesma Regional, uma movimentação diferente de tudo o que tínhamos visto até então, percebemos um fenômeno social relevante. Causou-nos estranhamento o fato de muitos jovens, vestidos com camisas iguais e manuseando constantemente o celular, estarem reunidos em um espaço como aquele, ouvindo músicas reproduzidas por aparelhos dos carros, dançando, bebendo e conversando. Decidimos então que aquele seria nosso campo, onde teríamos a situação e experiência etnográfica.

4. CAMPOS, Ricardo. Por que pintamos a cidade? uma abordagem etnográfica do graffiti urbano. Lisboa: Fim de Século, 2010; SILVEIRA, Fabrício Lopes. Outros grafites, outras topografias, outras medialidades. In: CAMPOS, Ricardo; BRIGHENTI, Andrea Mubi; SPINELLI, Luciano (Org.). Uma cidade de imagens: produções e consumos visuais em meio urbano. Lisboa: Mundos Sociais, 2011. p. 123-138. Para maior compreensão das relações entre juventude e redes sociais ver, entre outros: ALMEIDA, Maria Isabel Mendes; EUGENIO, Fernanda. O espaço real e o acúmulo que significa: uma nova gramática para se pensar o uso jovem da internet no Brasil. In: NICOLACI-DA-COSTA, Ana Maria (Org.) Cabeças digitais: o cotidiano na era da informação. São Paulo: Loyola, 2006. p. 49-80; BARBALHO, Alexandre. A criação está no ar: juventudes, política, cultura e mídia. Fortaleza: EdUECE, 2013; BRAGA, Adriana. Sociabilidades digitais e a reconfiguração das relações sociais. Desigualdade \& Diversidade: Revista de Ciências Sociais da PUC-Rio, Rio de Janeiro, n. 9, p. 95-104, ago./dez. 2011; DIÓGENES, Glória. Signos urbanos juvenis: rotas da pixação no ciberespaço. Cadernos de Campo, São Paulo, v. 22, n. 22, p. 45-61, 2013; JANOTTI JÚNIOR, Jeder Silveira. Mídia, cultura juvenil e rock and roll: comunidades, tribos e grupamentos urbanos. In: BARBALHO, Alexandre; PAIVA, Raquel Paiva (Org.). Comunicação e cultura das minorias. São Paulo: Paulus, 2005. p. 80-102; RIFIOTIS, Teophilos. Duas ou três coisas sobre elas, as comunidades virtuais. In: RIFIOTIS, Theophilos, et al. (Org.). Antropologia no ciberespaço. Florianópolis: Editora UFSC, 2010. 
5. MAGNANI, José GuiIherme Cantor. A rua e a evolução da sociabilidade. Cadernos de História de São Paulo, São Paulo, n. 2, jan./dez. 1993, p. 13.

6. CAMPOS, Ricardo. Identidade, imagem e representação na metrópole. In: CAMPOS, Ricardo; BRIGHENTI, Andrea Mubi; Spinelli, Luciano. Uma cidade de imagens: produções e consumos visuais em meio urbano. Lisboa: Mundos Sociais, 2011, p. 25.

7. LEMOS, André. Comunicação e práticas sociais no espaço urbano: as características dos dispositivos híbridos móveis de conexão multirrede (DHMCM). In: ANTOUN, Henrique (Org.). Web 2.0: participação e vigilância na era da comunicação distribuída. Rio de Janeiro: Mauad X, 2008, p. 51.

8. ROCHA, Everardo; PEREIRA, Cláudia. Sociabilidade e novas tecnologias: os significados do consumo entre os jovens. In: BARBOSA, Marialva; MORAIS, Oswaldo J. (Org.). Comunicação, cultura e juventude. São Paulo: Intercom, 2010.

9. A cidade de Fortaleza é dividida administrativamente em seis "regionais". A Regional VI é a maior delas, situada ao sul da cidade e composta por 27 bairros com diferentes perfis sociais, desde os habitados por famílias da classe média até aqueles com alguns dos mais baixos IDH da cidade.

10. BARBALHO; Alexandre; OLIVEIRA, Amanda Nogueira. Sociabilidades juvenis e o usos de dispositivos móveis na cidade. In: BARBALHO, Alexandre; MARÔPO Lidia (Org.). Infância, juventude e mídia: olhares luso-brasileiros. Fortaleza: UECE, 2015. p. 181-193.

\section{O EXERCÍCIO ETNOGRÁFICO: ALGUMAS CONSIDERAÇÕES}

A etnografia surgiu como recurso teórico-metodológico privilegiado diante da necessidade de acompanhar esse grupo que, como dito, se autodenominava "família", "Os poderosos e as poderosas"12.

Como o campo se constituiu também do ciberespaço, recorremos a uma forma específica de etnografia, a virtual ou netnografia. É um procedimento metodológico que se propõe a investigar interações mediadas e multissituadas a partir da inserção do pesquisador nos espaços que a internet proporciona ${ }^{13}$.

Como já discutido, o ciberespaço não é um ambiente dissociado das relações estabelecidas face a face, assim foi possível combinar as duas esferas de atuação (on-line e off-line), pensadas como estratégias solidárias, somando-se e existindo uma em função da outra, como "redes dobradas".

A necessidade de trabalhar com a netnografia como procedimento para pesquisas em ambientes comunicacionais se colocava também pelo caráter rápido das mutações nas sociedades em que estamos inseridos. Como situa Margulis, "partes de la ciudad son decodificadas de modo diferente por las varias generaciones, que les otorgan distinto uso o bien las perciben y vivencian de manera nueva, porque cada nueva generación se socializa con nuevas pautas de percepción y apreciación"14.

Portanto, coube à pesquisa etnográfica possibilitar o entendimento dessas transformações em meio ao grupamento social. Na etnografia, vê-se o quanto o pesquisador é parte inextrincável na compreensão dos sentidos e das ações dos interlocutores essenciais da pesquisa. Como situa James Clifford, a prática etnográfica deve ser entendida "não como a experiência e a interpretação de uma 'outra' realidade circunscrita, mas sim como uma negociação construtiva envolvendo pelo menos dois, e muitas vezes mais, sujeitos conscientes e politicamente significativos"15.

As pesquisas etnográficas, de fato, têm como uma de suas características mais fortes o caráter dialógico no campo. Não há possibilidade de o pesquisador se encaixar como "uma mosca na parede", paralisado em meio ao turbilhão de acontecimentos, comportando-se apenas como observador ${ }^{16}$. A condição de etnógrafo é o contrário dessa postura inerte. Desde o primeiro momento o pesquisador está presente, engajando-se na vida cotidiana daqueles com os quais lida em sua pesquisa.

Neste caso, uma das maiores preocupações na aproximação e no posterior vínculo estabelecido com a família "Os poderosos e as poderosas" foi justamente essa dimensão da participação etnográfica. Como nos encaixar no coletivo? Como ser aceitos, participar dos momentos gerados, dos encontros semanais e fazer que nossa presença interviesse o mínimo possível no cotidiano desse grupo? Posteriormente, observamos que eram perguntas "ingênuas", posto que necessariamente nossa inserção, fosse da forma que fosse, interviria no grupamento com o qual estávamos nos relacionando. 
Poderíamos caracterizar a etnografia, portanto, como "uma empreitada que supõe trabalho paciente e continuado, ao cabo do qual, ou em algum momento, elementos dispersos se ordenam, perfazendo um significado até mesmo inesperado"17. Ora, esse caráter inesperado é obtido a partir da proximidade do pesquisador com o grupo estudado, por meio dos vínculos gerados e do fortalecimento de laços criados na pesquisa.

Por sua vez, mesmo que a pesquisa resulte em alguma forma de intervenção no coletivo estudado, há de se entender também que é preciso algum olhar distanciado perante as ações e produções de sentidos dos atores e atrizes sociais, como uma espécie de modulação entre o estar "de fora e de longe" e o estar "de perto e de dentro". Essa modulação se faz necessária na medida em que há um limite, nem sempre muito claro, entre as zonas de participação do pesquisador enquanto narrador e até tradutor cultural de ações e atitudes e do pesquisador enquanto pessoa interagente.

\section{A PRÁTICA ETNOGRÁFICA: ENTRE O CELULAR E A PRAÇA}

Um dos principais instrumentos utilizados para alcançar essa modulação foi o diário de campo, trazendo à tona, além dos fatos com os quais lidamos, impressões cotidianas, sentimentos envolvidos e dúvidas surgidas durante todo o processo. $\mathrm{O}$ ato de registrar no diário não pode ser entendido como algo simples, principalmente quando se estabelece o exercício ininterrupto da escuta comprometida, em que se cria um canal de atenção entre pesquisador e grupo acompanhado. O processo de produção de relatos de campo é um intenso descortinar de situações, e não há modelo a ser seguido. Como destaca Latour, "se um dado conjunto aí está pura e simplesmente, então é invisível e nada se pode dizer a seu respeito. O conjunto não deixa rastros e, portanto, não gera nenhuma informação; se é visível, está se fazendo e gerará dados novos e interessantes"18.

Também fez parte do processo a realização de entrevistas, que possibilitaram uma visão mais individualizada dos sentidos do grupo. Esse foi o que podemos chamar de um dos desdobramentos da prática etnográfica, quando a escrita reflexiva começou a despontar. Com o tempo, a necessidade de compreensão acerca do dito e do não dito apareceu cada vez mais frequentemente, gerando uma espécie de escrita interpretativa.

A pesquisa ocorreu entre março de 2015, época em que conhecemos a "família", e novembro do mesmo ano, quando conseguimos verificar uma quantidade expressiva de material levantado. Foram cerca de dez meses de participação intensa, evidenciada tanto pelo uso contínuo do celular como pelas idas aos encontros da família. Os locais de pesquisa, portanto, foram os grupos do WhatsApp, nos quais fomos inseridos, e as praças onde aconteciam os encontros semanais propostos pela família. Cabe salientar que todos os interlocutores e interlocutoras com os quais mantivemos contato sabiam da justificativa para nossa participação ativa na "família poderosa".
11. SIBILIA, Paula. O homem pós-orgânico: corpo, subjetividade e tecnologias digitais. Rio de Janeiro: Relume-Dumará, 2002.

12. Nome fictício dado pelos pesquisadores. A nocão êmica de "família" não considera consanguinidade e laços parentais, mas se refere a vínculos de diferentes naturezas. Como forma de reconhecimento de si e do outro, a noção está mais próxima das de amizade, ajuda mútua e solidariedade (SOUZA, Luciana Karine; GAUER, Gustavo. Uma história do conceito de amizade. In: HUTZ, Claudio Simon; SOUZA, Luciana Karine de (Org.). Amizade em contexto: desenvolvimento e cultura. São Paulo: Casa do Psicólogo, 2012. p. 41-63). Não há somente a família "Os poderosos e as poderosas". Obtivemos conhecimento da existência de pelo menos quinze outras no âmbito da Regional $\mathrm{Vl}$, onde ocorreu a pesquisa, e cerca de vinte grupamentos em outras localidades.

13. POLIVANOV, Beatriz. Etnografia virtual, netnografia ou apenas etnografia?: implicações dos conceitos. Esferas, Brasília, ano 2, n. 3, p. 61-71, jul./ dez. 2013; RIFIOTIS, Teophilos. Duas ou três coisas sobre elas, as comunidades virtuais, op. cit.

14. MARGULIS, Mario. Sociologia de la cultura: conceptos y problemas. Buenos Aires: Biblos, 2009, p. 91.

15. CLIFFORD, James. A experiência etnográfica: antropologia e literatura no século XX. Rio de Janeiro: UFRJ, 2002, p. 43.

16. EMERSON, Robert M.; FRETZ, Rachel I.; SHAW, Linda L. Notas de campo na pesquisa etnográfica. Tendências: Caderno de Ciências Sociais, Crato/ CE, n. 7, p. 355-383, 2013. 
Durante o período de pesquisa, estivemos inseridos em cinco grupos dessa "família" no WhatsApp, sendo que dois deles foram abolidos pelo próprio grupamento. Estivemos presente, na maior parte do tempo, em três grupos: o geral, onde permanecem todos os integrantes, o do bonde feminino ${ }^{19}$, que congrega as que se reconhecem desse gênero, inclusive mulheres trans, e o da diretoria, composto pelos jovens que regem a família, como pode ser observado nas Figuras 1 a 3.

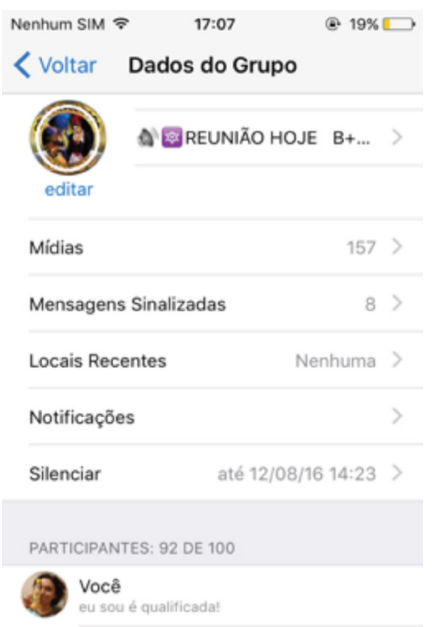

Figura 1: Grupo geral da família "Os poderosos e as poderosas"

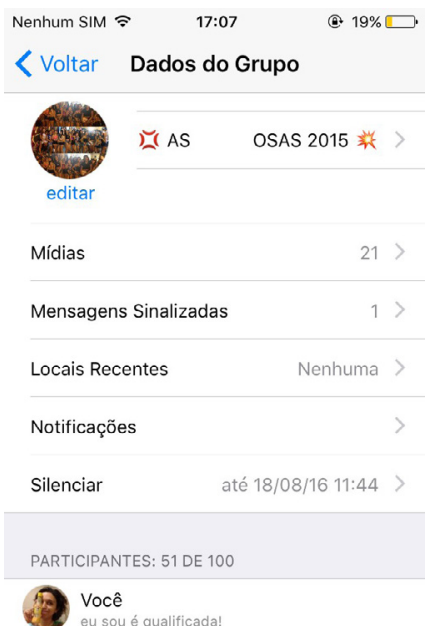

Figura 2: Grupo das poderosas

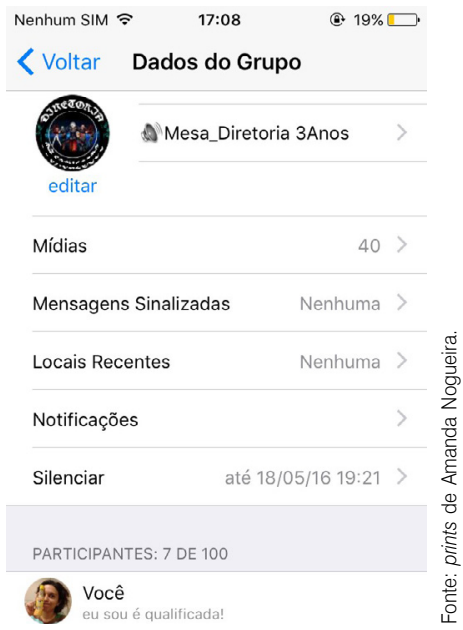

Figura 3: Grupo da diretoria da família "Os poderosos e as poderosas"
17. MAGNANI, José GuiIherme Cantor. Da periferia ao centro: trajetórias de pesquisa em antropologia urbana. São Paulo: Terceiro Nome, 2012.

18. LATOUR, Bruno. Reagregando o social: uma introdução à teoria do ator-rede. Salvador: EdUFBA, 2012, p. 54.

19. Termo que denota a proximidade com algumas nomenclaturas utilizadas pelo funk carioca, mas ressignificado pela família ao ser utilizado como sinônimo de ajuntamento de galeras independentemente de qualquer corrente musical.

A proposta, ao entrar nesses grupos, era a de absorver informações imagens, fotografias, áudios e outros registros - que facilitassem a nossa compreensão acerca da família. A busca de dados se deu primordialmente a partir dos prints e do envio das imagens por correio eletrônico para a caixa de mensagens da pesquisa.

No primeiro momento, enviávamos as conversas por correio eletrônico, a partir da opção que o próprio WhatsApp oferecia. No entanto, o envio permitia apenas arquivos de texto de bloco de notas, o que dificultava bastante a compreensão das relações estabelecidas, já que os emojis sumiam do arquivo e davam lugar a diversos quadradinhos.

Ora, os emojis, também chamados de "carinhas" por parte de alguns jovens, estabeleciam outros sentidos ao texto. Seria o que podemos chamar de retorno a um tipo de oralidade transcrita. Em meio aos repertórios criados pelos próprios componentes da "família poderosa", percebemos o quanto as marcas da comunicação oral estiveram presentes. Palavras eram escritas especialmente do modo como eles falavam. As construções frasais nas mensagens de texto correspondiam mais à forma oral que à representação escrita. 
A oralidade transcrita exercida em aplicativos de bate-papo, como acontece no WhatsApp, é realizada a partir da junção de diferentes formas de recursos textuais e nem sempre há uma compreensão total da mensagem previamente estabelecida, como pode ser percebido nas Figuras 4 a 6. Foi a partir dessa percepção que passamos a printar e guardar as imagens em pastas, separadas por categoria:

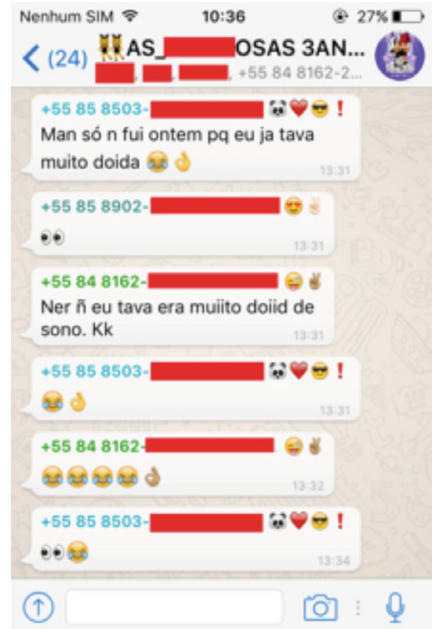

Figura 4: Início de diálogo no grupo das poderosas. Grupo 1.

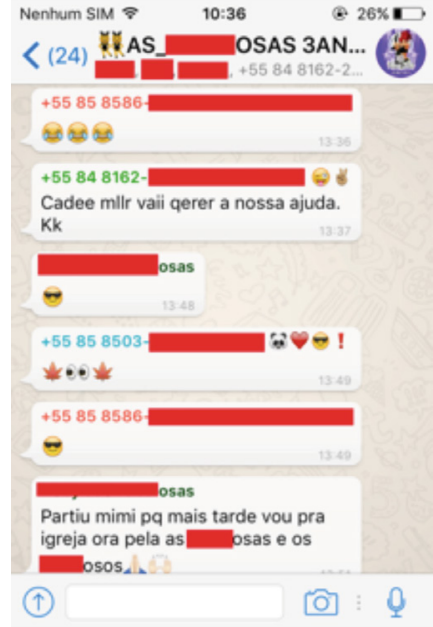

Figura 5: Continuação de diálogo no grupo das poderosas. Grupo 1.

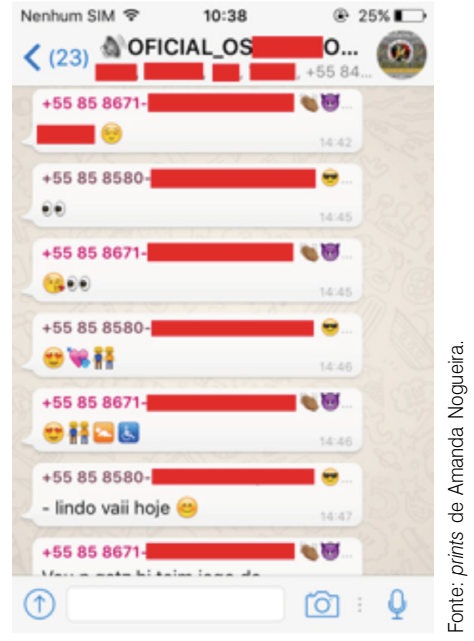

Figura 6: Diálogo no grupo geral da família poderosa. Grupo 2.

Para acompanhar os registros obtidos no Whatsapp e entender se aquelas formas como as pessoas se relacionavam ocorriam também na praça, passamos a ir praticamente a todos os encontros semanais programados pela família poderosa. As Figuras 7 e 8 mostram alguns desses momentos.

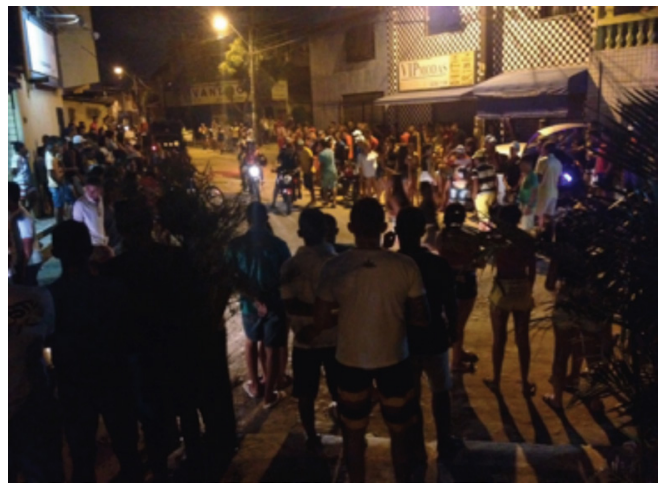

Figura 7: Registro de um dos encontros da família poderosa na Praça do Alecrim.

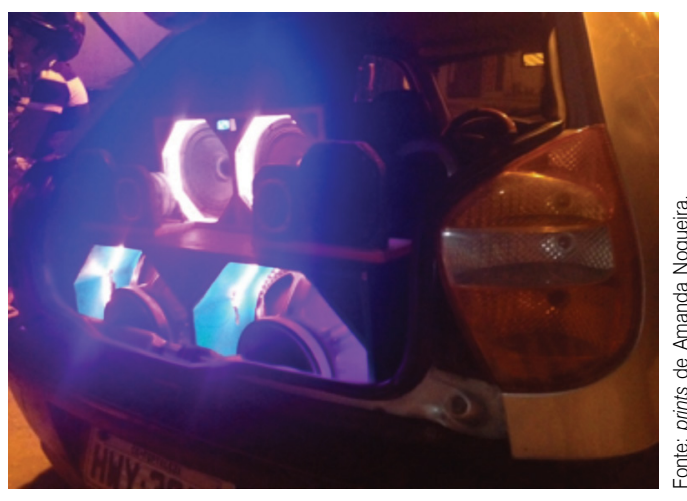

Figura 8: O carro de som, sempre presente, era um fator agregativo intenso. 
Em meio à profusão de jovens que participam tanto dos grupos no WhatsApp como dos encontros nas praças, sentimos a necessidade, como já exposto, de realizar entrevistas a fim de compreender ainda melhor cada ator e atriz social interagente nesse processo. Ao todo, mantivemos relação próxima com cerca de vinte jovens, o que favoreceu a produção de sete entrevistas. Dialogamos especialmente com jovens que participavam ativamente dos encontros nas praças, ao mesmo tempo que também utilizavam o celular como ambiente de interação. Eram jovens que praticamente em todos os dias de encontro nas praças marcavam presença e também compartilhavam seus pensamentos no WhatsApp.

Optamos por entrevistas semiestruturadas que permitiram, a partir de perguntas semidiretivas, dialogar sobre pontos de controvérsia com os quais havíamos nos deparado por meio do acompanhamento da família em campo. Para tais entrevistas, optamos por seguir um mínimo de padronização, a fim de comparar posteriormente respostas de diferentes interlocutores.

Mesmo trabalhando em ambientes digitais, decidimos dialogar com nossos interlocutores face a face, e isso foi também um pedido expresso de alguns deles. Em certas entrevistas, tivemos de visitá-los em casa e conhecemos sua realidade mais de perto. Como discutido anteriormente, não tínhamos receio de que essa proximidade pudesse "atrapalhar" o processo. Acreditamos, pelo contrário, que a forma como dialogamos com nossos interlocutores possibilitou acessar essas narrativas pessoais e "familiares".

Também registramos em fotografias e vídeos vários momentos em que acompanhamos a família poderosa. Todo o material empírico revelou quem eram esses jovens e de que modo participamos de cada momento, assim como nos permitiu entender com mais clareza as formas relacionais tecidas.

Por fim, é necessário destacar que foram criteriosamente escolhidos todos os registros imagéticos - prints, fotografias, imagens de divulgação dos encontros compartilhados por WhatsApp -, sendo deixados devidamente anônimos todos os participantes, por meio de pequenas tarjas em seus nomes, rostos, corpos e números de telefone. No caso dos entrevistados, optamos por pedir a cada um que sugerisse outro nome, que não o deles, para designá-los na pesquisa, assim como escolhemos uma nomenclatura diferente para a família.

\section{REFERÊNCIAS BIBLIOGRÁFICAS}

ALMEIDA, Maria Isabel Mendes; EUGENIO, Fernanda. O espaço real e o acúmulo que significa: uma nova gramática para se pensar o uso jovem da internet no Brasil. In: NICOLACI-DA-COSTA, Ana Maria (Org.) Cabeças digitais: o cotidiano na era da informação. São Paulo: Loyola, 2006. p. 49-80.

BARBALHO, Alexandre. A criação está no ar: juventudes, política, cultura e mídia. Fortaleza: EdUECE, 2013. 
BARBALHO; Alexandre; OLIVEIRA, Amanda Nogueira. Sociabilidades juvenis e o usos de dispositivos móveis na cidade. In: BARBALHO, Alexandre; MARÔPO, Lidia (Org.). Infância, juventude e mídia: olhares luso-brasileiros. Fortaleza: UECE, 2015. p. 181-193.

BRAGA, Adriana. Sociabilidades digitais e a reconfiguração das relações sociais. Desigualdade \& Diversidade: Revista de Ciências Sociais da PUC-Rio, Rio de Janeiro, n. 9, p. 95-104, ago./dez. 2011. Disponível em: <http://bit. ly/2aN9byP $>$. Acesso em: 16 set. 2017.

CAMPOS, Ricardo. Identidade, imagem e representação na metrópole. In: CAMPOS, Ricardo; BRIGHENTI, Andrea Mubi; Spinelli, Luciano. Uma cidade de imagens: produções e consumos visuais em meio urbano. Lisboa: Mundos Sociais, 2011.

Por que pintamos a cidade?: uma abordagem etnográfica do graffiti urbano. Lisboa: Fim de Século, 2010.

CLIFFORD, James. A experiência etnográfica: antropologia e literatura no século XX. Rio de Janeiro: UFRJ, 2002. p. 17-62.

DIÓGENES, Glória. Signos urbanos juvenis: rotas da pixação no ciberespaço. Cadernos de Campo, São Paulo, v. 22, n. 22, p. 45-61, 2013. Disponível em: $<$ http://bit.ly/2fGuEgI>. Acesso em 15 set. 2017.

EMERSON, Robert M.; FRETZ, Rachel I.; SHAW, Linda L. Notas de campo na pesquisa etnográfica. Tendências: Caderno de Ciências Sociais, Crato/CE, n. 7, p. 355-383, 2013. Disponível em: <http://bit.ly/2wbfKoN>. Acesso em: 14 set. 2017.

JAIDE, Walter. As ambiguidades do conceito de "geração". In: BRITTO, Sulamita de (Org.). Sociologia da juventude II: para uma sociologia diferencial. Rio de Janeiro: Zahar, 1968. p. 15-28.

JANOTTI JÚNIOR, Jeder Silveira. Mídia, cultura juvenil e rock and roll: comunidades, tribos e grupamentos urbanos. In: BARBALHO, Alexandre; PAIVA, Raquel Paiva (Org.). Comunicação e cultura das minorias. São Paulo: Paulus, 2005. p. 80-102.

LATOUR, Bruno. Reagregando o social: uma introdução à teoria do atorrede. Salvador: EdUFBA, 2012.

LEMOS, André. Comunicação e práticas sociais no espaço urbano: as características dos dispositivos híbridos móveis de conexão multirrede (DHMCM). In: ANTOUN, Henrique (Org.). Web 2.0: participação e vigilância na era da comunicação distribuída. Rio de Janeiro: Mauad X, 2008. p. 45-62. MAGNANI, José Guilherme Cantor. Da periferia ao centro: trajetórias de pesquisa em antropologia urbana. São Paulo: Terceiro Nome, 2012. 
. A rua e a evolução da sociabilidade. Cadernos de História de São Paulo, São Paulo, n. 2, jan./dez. 1993.

MARGULIS, Mario. Sociologia de la cultura: conceptos y problemas. Buenos Aires: Biblos, 2009.

MILLS, Wright. A imaginação sociológica. Rio de Janeiro: Zahar, 1969.

POLIVANOV, Beatriz. Etnografia virtual, netnografia ou apenas etnografia?: implicações dos conceitos. Esferas, Brasília, ano 2, n. 3, p. 61-71, jul./dez. 2013.

RIFIOTIS, Teophilos. Duas ou três coisas sobre elas, as comunidades virtuais. In: RIFIOTIS, Theophilos, et al. (Org.). Antropologia no ciberespaço. Florianópolis: Editora UFSC, 2010.

ROCHA, Everardo; PEREIRA, Cláudia. Sociabilidade e novas tecnologias: os significados do consumo entre os jovens. In: BARBOSA, Marialva; MORAIS, Oswaldo J. (Org.). Comunicação, cultura e juventude. São Paulo: Intercom, 2010.

SIBILIA, Paula. O homem pós-orgânico: corpo, subjetividade e tecnologias digitais. Rio de Janeiro: Relume-Dumará, 2002.

SILVEIRA, Fabrício Lopes. Outros grafites, outras topografias, outras medialidades. In: CAMPOS, Ricardo; BRIGHENTI, Andrea Mubi; SPINELLI, Luciano (Org.). Uma cidade de imagens: produções e consumos visuais em meio urbano. Lisboa: Mundos Sociais, 2011. p. 123-138.

SOUZA, Luciana Karine; GAUER, Gustavo. Uma história do conceito de amizade. In: HUTZ, Claudio Simon; SOUZA, Luciana Karine de (Org.). Amizade em contexto: desenvolvimento e cultura. São Paulo: Casa do Psicólogo, 2012. p. 41-63. 